\title{
HUBUNGAN KONDISI FISIK RUMAH DENGAN KEJADIAN PENYAKIT TBC PARU DI WILAYAH KERJA PUSKESMAS SIMOMULYO KOTA SURABAYA TAHUN 2019
}

Nur Anisah Apriliani, Umi Rahayu, Narwati

Jurusan Kesehatan Lingkungan Poltekkes Kemenkes Surabaya

Email : nuranisah.apriliani@gmail.com

\begin{abstract}
ABSTRAK
Kondisi fisik rumah di wilayah kerja Puskesmas Simomulyo berdempetan, sehingga mempengaruhi kualitas ruang pada rumah. Kondisi tersebut dapat mempengaruhi kejadian penyakit TBC Paru. Tujuan penelitian ini untuk mengetahui hubungan kondisi fisik rumah dengan kejadian penyakit TBC Paru di Wilayah Kerja Puskesmas Simomulyo.

Jenis penelitian ini adalah analitik observasional dengan pendekatan kasus kontrol (perbandingan $1: 1$ ). Sampel kasus 60 rumah dan sampel kontrol 60 rumah yang diambil secara acak dengan simple random sampling. Data dianalisis melalui uji Chi-Square pada tingkat kepercayaan $95 \%(a \dot{a}=0.05)$.

Hasil penelitian menunjukkan adanya hubungan antara pencahayaan ( $p$-value= $0,009)$, kelembapan ( $p$-value $=0,001)$, suhu ( $p$-value 0,007$)$, Ventilasi $(p$-value $=0,004)$, Kepadatan Hunian $(p$-value $=0,019)$, Lantai $(p$-value $=0,039)$ Lubang Asap Dapur $(p-$ value $=0,001$ ), kondisi fisik rumah ( $p$-value $=0,030$ ) dengan penyakit TBC Paru. Hal ini diperhatikan dengan kondisi fisik rumah yang tidak memenuhi syarat sesuai Keputusan Menteri Kesehatan Nomor 829/Menkes/SK/VII/1999 tentang persyaratan kesehatan perumahan dan rumah tinggal.

Kesimpulan dari penelitian ini adalah ada pengaruh hubungan kondisi fisik rumah dengan kejadian penyakit TBC Paru. Saran bagi masyarakat agar peduli terhadap kondisi lingkungan rumah, memasang genteng kaca, membuka jendela setiap pagi, menjaga kebersihan diri, menerapkan etika batuk, dan menggunakan masker apabila batuk dan pilek.
\end{abstract}

Kata kunci: Kondisi Fisik Rumah, Penyakit TBC Paru

\section{PENDAHULUAN}

Pembangunan kota - kota besar di Indonesia tumbuh dan berkembang tidak dari penduduk di kota itu sendiri, melainkan juga datang dari penduduk luar kota yang ingin tinggal serta turut membangun kota. Dengan semakin bertumbuhnya pembangunan di wilayah kota, maka tumbuh pula penduduk yang memerlukan tempat tinggal, terutama tempat tinggal yang dekat dengan sumber mata pencaharian. Lingkungan tempat tinggal sangat berpengaruh terhadap kesehatan masyarakat yang bertempat tinggal disekitar lingkungan padat huni dan kumuh. Masalah kesehatan yang berhubungan dengan tempat tinggal adalah masalah kebersihannya, pembuangan kotoran manusia, pengelolaan sampah, kualitas udara (suhu dan kelembapan) dan pencahayaan didalam rumah, kepadatan hunian, ventilasi kamar hunian (Girsang, 2007).

Tuberkulosis adalah penyakit yang disebabkan infeksi bakteri Mycobacterium tuberculosis. TBC Paru tersebar lewat udara bila orang yang mengidap TB di paru-paru atau tenggorokan saat batuk, bersin atau berbicara dapat menularkan ke udara. Gejala TBC Paru yaitu batuk yang berlangsung lebih dari 3 minggu, demam, berat badan turun tanpa sebab, keringat malam, senantiasa lelah, nafsu makan berkurang, dan dahak bebercak darah. Pencegahan terhadap penyakit TBC Paru dengan cara penderita TBC Paru diminta menutupi hidung dan mulutnya apabila mereka batuk atau bersin, pemberian vaksin BCG dapat melindungi anak-anak yang bepergian ke negara yang biasa kejangkitan TBC Paru. Pengobatan penyakit TBC Paru diobati dengan gabungan antibiotika khusus 
setidaknya 6 bulan. Antibiotika TBC Paru ini diminum di bawah pengawasan perawat klinik guna memperhatikan dampak sampingnya dan meyakinkan pengobatannya sudah selesai. Penderita TBC Paru dapat sembuh jika menyelesaikan pengobatan. Jika tidak minum obat, pengidapnya bisa menjadi sakit parah, bahkan meninggal (Health NSW, 2005).

Rumah sehat yaitu bangunan tempat tinggal yang memenuhi persyaratan kesehatan yang terdiri dari komponen rumah, sarana sanitasi dan perilaku dengan memiliki akses jamban sehat, tempat pembuangan sampah, sarana air bersih, sarana pembuangan air limbah, ventilasi baik, kepadatan hunian rumah memenuhi persyaratan, dan lantai rumah tidak terbuat dari tanah (Dinas Kesehatan Provinsi Jawa Timur, 2017). Rumah yang dihuni di Indonesia, menurut data Riskesdas 2010 menunjukkan bahwa secara nasional $24,9 \%$ yang tergolong rumah sehat, sisanya belum memenuhi kriteria rumah sehat. Penilaian terhadap rumah sehat ini dilakukan terhadap kriteria kondisi fisik rumah yang meliputi atap, dinding, lantai, ketersediaan jendela, ventilasi, pencahayaan, lantai, kepadatan hunian. Selain itu terdapat faktor risiko lingkungan lainnya pada bangunan rumah yang dapat berpengaruh terhadap kejadian penyakit TBC Paru antara lain : kelembapan, kualitas udara dalam ruang, serta perilaku meludah di sembarangan tempat, batuk tanpa menutup mulut, pengobatan yang tidak teratur, tidak membuka jendela, dan tidak memakai masker (Mahmuda, 2014).

Tujuan dari penelitian ini yaitu untuk Untuk mengetahui hubungan kondisi fisik rumah dengan kejadian TBC Paru di Wilayah kerja Puskesmas Simomulyo.

\section{METODE PENELITIAN}

Penelitian ini termasuk dalam jenis penelitian penelitian deskriptif analitik, yang artinya penelitian untuk mendeskripsikan atau memberi gambaran terhadap objek yang diteliti melalui data atau sampel yang telah terkumpul lalu mencoba menggali bagaimana dan mengapa fenomena kesehatan itu terjadi. Kemudian melakukan analisis dinamika korelasi antara fenomena atau antara faktor risiko denga faktor efek. Yang dimaksud faktor efek adalah suatu akibat dari adanya faktor risiko, sedangkan faktor risiko adalah suatu fenomena yang mengakibatkan terjadinya efek (Notoatmojo,2011:37)

Penelitian ini menggunakan pendekatan case control yaitu suatu penelitian analitik yang menyangkut bagaimana faktor risiko dipelajari, dengan menggunakan pendekatan retrospective. Dengan kata lain, efek (penyakit atau status kesehatan) diidentifikasi pada saat ini, kemudian faktor risiko diindentifikasi pada saat terjadinya waktu lalu (Notoadmojo,2011:41).

Variabel terikat dalam penelitian ini adalah Penyakit TBC Paru. Variabel bebasnya adalah ventilasi, kelembapan, suhu, pencahayaan, dan kepadatan hunian, lantai, lubang asap dapur.

Teknik pengumpulan data menggunakan teknik observasi untuk mengamati secara langsung terhadap kondisi ventilasi, suhu, kelembapan, pencahayaan, kepadatan hunian, lantai, dan lubang asap dapur di rumah responden. Selain itu juga melakukan wawancara untuk mengetahui karakteristik dan penyakit responden. Data sekunder didapatkan dari Dinas Kesehatan Kota Surabaya dan Puskesmas Simomulyo, yang meliputi data penderita penyakit TBC Paru dan data jumlah rumah penderita TBC Paru di wilayah kerja Puskesmas Simomulyo.

\section{HASIL DAN PEMBAHASAN \\ Hubungan Kondisi Fisik Rumah dan kejadian Penyakit TBC Paru di Wilayah Kerja Puskesmas Simomulyo Kota Surabaya}

Dapat diketahui bahwa bahwa pencahayaan yang memenuhi syarat dengan kejadian penyakit TBC sebanyak 11 rumah $(18,3 \%)$ dan pencahayaan yang tidak memenuhi syarat dengan kejadian penyakit TBC Paru sebanyak 49 rumah (81,7\%). Sedangkan untuk pencahayaan yang memenuhi syarat 
dengan tidak disertai kejadian penyakit TBC sebanyak 24 rumah (40\%). Dan pencahayaan yang tidak memenuhi syarat dengan tidak disertai kejadian penyakit TBC Paru sebanyak 36 rumah $(60 \%)$.

Berdasarkan hasil Statistik yaitu uji Chi-Square yang menyatakan bahwa ada hubungan pencahayaan dengan kejadian penyakit TBC Paru di wilayah kerja Puskesmas Simomulyo Kota Surabaya ( $p$ $0,009<0,05)$. Dimana pencahayaan yang tidak memenuhi persyaratan dikarenakan kurang nya cahaya yang masuk ke dalam rumah dan kamar penderita serta cahaya buatan yang terlalu minim pada ruangan. dengan didukung hasil pengukuran pencahayaan, terdapat hasil yang tidak memenuhi syarat, dampak dari pencahayaan yang tidak memenuhi syarat, yaitu kelembapan tinggi dan suhu semakin minus dapat berakibat berkembang nya Mycobacterium tuberculosis di dalam rumah dan penularan akan semakin meningkat.

Kelembapan diperoleh hasil bahwa yang memenuhi syarat dengan kejadian penyakit TBC Paru sebanyak 8 rumah $(13,3 \%)$ dan kelembapan yang tidak memenuhi syarat dengan kejadian penyakit TBC Paru sebanyak 52 rumah $(86,7 \%)$. Sedangkan untuk kelembapan yang memenuhi syarat dengan tidak disertai kejadian penyakit TBC Paru sebanyak 25 rumah (41,7\%). Dan kelembapan yang tidak memenuhi syarat dengan tidak disertai kejadian penyakit TBC Paru sebanyak 35 rumah $(58,3 \%)$ hasil ini diakibatkan karena kelembapan yang ada pada rumah yang diteliti kondisi lembab, dengan penilaian yang kurang dari persyaratan kelembapan udara $60 \%$.

Dari hasil uji statistik yaitu uji ChiSquare didapatkan hasil bahwa ada hubungan kelembapan dengan kejadian penyakit TBC Paru di Wilayah Kerja Puskesmas Simomulyo Kota Surabaya ( $p$ $0,001<0,05)$. hasil ini diakibatkan karena kelembapan yang ada pada rumah yang diteliti kondisi kelembaban tinggi, daerah pemukiman padat penduduk, ventilasi dan pencahayaan yang kurang memenuhi syarat serta adanya penilaian yang dilakukan dengan pengukuran kelembapan di dalam rumah didapatkan hasil yang kurang memenuhi syarat kelembapan.

Suhu yang diperoleh dari penelitian dibedakan sebagai berikut, memenuhi syarat dengan kejadian penyakit TBC Paru sebanyak 13 rumah $(21,7 \%)$ dan ventilasi yang tidak memenuhi syarat dengan kejadian penyakit TBC sebanyak 47 rumah $(78,3 \%)$. Sedangkan untuk ventilasi yang memenuhi syarat dengan tidak disertai kejadian penyakit TBC Paru sebanyak 27 rumah (45\%). Dan ventilasi yang tidak memenuhi syarat dengan tidak disertai kejadian penyakit TBC Paru sebanyak 33 rumah (55\%).

Dari hasil uji statistik yaitu uji ChiSquare didapatkan hasil bahwa ada hubungan ventilasi dengan kejadian penyakit TBC Paru di Wilayah Kerja Puskesmas Simomulyo Kota Surabaya ( $P$ $<0,05)$. Hal ini dikarenakan pemukiman padat penduduk, tidak terdapat lubang asap dapur, kondisi kelembapan di dalam rumah tinggi dan ventilasi yang berada di dalam rumah tidak ada, walaupun terdapat ventilasi akan tetapi tidak berfungsi sebagaimana mestinya, sehingga mengakibatkan suhu di dalam kamar dan rumah tidak dapat berputar dan berganti, akibat nya di dalam kamar dan rumah terasa dingin dan merasa sesak, kondisi tersebut berpengaruh besar terhadap berkembangnya penularan Mycobacterium tuberculosis di dalam rumah.

Kondisi ventilasi yang memenuhi syarat dengan kejadian penyakit TBC sebanyak 9 rumah (15\%) dan ventilasi yang tidak memenuhi syarat dengan kejadian penyakit TBC Paru sebanyak 51 rumah (85\%). Sedangkan untuk ventilasi yang memenuhi syarat dengan tidak disertai kejadian penyakit TBC Paru sebanyak 23 rumah $(38,3 \%)$. Dan ventilasi yang tidak memenuhi syarat dengan tidak disertai kejadian penyakit TBC Paru sebanyak 37 rumah $(61,7 \%)$.

Dari hasil uji statistik yaitu uji ChiSquare didapatkan hasil bahwa ada hubungan ventilasi dengan kejadian penyakit TBC Paru di Wilayah Kerja 
Puskesmas Simomulyo Kota Surabaya ( $p$ $0,004<0,05)$. Dimana ventilasi yang tidak memenuhi syarat tersebut, dikarenakan ukuran ventilasi yang tidak sebanding dengan luas lantai rumah $<10 \%$ dari luas lantai rumah, dikarenakan rumah yang padat penghuni dengan ukuran $4 \mathrm{~m} \times 1 \mathrm{~m}$, tidak terdapat ventilasi di rumah walaupun ada, akan tetapi ventilasi tidak berfungsi sebagaimana mestinya. Mengakibatkan kondisi di dalam rumah tersebut tidak ada sirkulasi udara, didukung dengan suhu minus dan kelembapan tinggi berpengaruh terhadap penularan Mycobacterium tuberculosis di dalam rumah.

Kepadatan hunian yang memenuhi syarat dengan kejadian penyakit TBC Paru sebanyak 9 rumah (15\%) dan kepadatan hunian yang tidak memenuhi syarat dengan kejadian penyakit TBC Paru sebanyak 51 rumah (85\%). Sedangkan untuk kepadatan hunian yang memenuhi syarat dengan tidak disertai kejadian penyakit TBC Paru sebanyak 20 rumah $(66,7 \%)$. Dan kepadatan hunian yang tidak memenuhi syarat dengan tidak disertai kejadian penyakit TBC Paru sebanyak 40 rumah $(33,3 \%)$.

Dari hasil statistik yaitu uji Chi-Square didapatkan hasil bahwa ada hubungan kepadatan hunian dengan kejadian penyakit TBC Paru di Wilayah Kerja Puskesmas Simomulyo Kota Surabaya ( $p$ $0,019<0,05)$. Dimana rumah yang memiliki kepadatan hunian yang tidak memenuhi syarat tersebut dikarenakan penghuni kamar disetiap rumah $<8$ $\mathrm{m}^{2} / 2$ orang, yang artinya dalam 1 kamar yang mayoritas berukuran sekitar $7 \mathrm{~m}^{2} /$ orang ditempati 2 orang atau lebih. Kondisi tersebut dikarenakan banyak penderita TBC Paru yang hidup di pemukiman padat penduduk, tidak terdapat ventilasi, suhu minus dan kelembapan tinggi, pencahayaan minim, tidak terdapat lubang asap dapur, kondisi lantai rumah yang masih dari tanah liat, faktor - faktor fisik tersebut sangat berpengaruh dalam penularan TBC Paru di dalam rumah. Penelitian ini sejalan dengan penelitian (Kurniasih,2016) dengan hasil statistik hasil analisa uji Chi-
Square $(p 0,023<0,05)$ dan sejalan dengan penelitian Mawardi dan Meilya Farika Indah (2014) dengan hasil statistik hasil analisa uji Chi-Square ( p 0,006 < 0,05 ).

Kondisi lantai yang memenuhi syarat dengan kejadian penyakit TBC Paru sebanyak 11 rumah $(18,3 \%)$ dan lantai yang tidak memenuhi syarat dengan kejadian penyakit TBC Paru sebanyak 49 rumah $(81,7 \%)$. Sedangkan untuk lantai yang memenuhi syarat dengan tidak disertai kejadian penyakit TBC Paru sebanyak 21 rumah (35\%). Dan lantai yang tidak memenuhi syarat dengan tidak disertai kejadian penyakit TBC Paru sebanyak 39 rumah (65\%).

Dari hasil statistik yaitu uji Chi-Square didapatkan hasil bahwa tidak ada hubungan lantai dengan kejadian penyakit TBC di Wilayah Kerja Puskesmas Simomulyo Kota Surabaya (p 0,039 < 0,05 ). Dimana yang tidak memiliki lantai yang memenuhi syarat, tidak terdapat lapisan keramik/plester/ubin pada kondisi lantai rumah yang ada yaitu kedap air, lalu suhu minus, ruangan lembab, dan dingin oleh karena jenis lantai kedap air, suhu minus dan ruangan lembab merupakan salah satu faktor risiko kejadian TBC Paru karena bakteri penyebab TBC Paru dapat bertahan hidup di tempat yang lembab, dingin, tidak ada cahaya matahari masuk, tidak terdapat pertukaran udara, pengap, dan sesak.

Keadaan lubang asap dapur yang memenuhi syarat dengan kejadian penyakit TBC Paru sebanyak 9 rumah (15\%) dan lubang asap dapur yang tidak memenuhi syarat dengan kejadian penyakit TBC Paru sebanyak 51 rumah (85\%). Sedangkan untuk lubang asap dapur yang memenuhi syarat dengan tidak disertai kejadian penyakit TBC Paru sebanyak 26 rumah (43,3\%). Dan lubang asap dapur yang tidak memenuhi syarat dengan tidak disertai kejadian penyakit TBC Paru sebanyak 34 rumah $(56,7 \%)$.

Dari hasil uji statistik yaitu uji ChiSquare didapatkan hasil bahwa ada hubungan lubang asap dapur dengan kejadian penyakit TBC Paru di Wilayah Kerja Puskesmas Simomulyo Kota 
Surabaya ( p 0,001 < 0,05). Dimana lubang asap dapur yang tidak memenuhi syarat, dikarenakan kondisi rumah yang padat hunian dan ukuran lubang asap dapur $<10 \%$ dari luas lantai dapur dan tidak terdapat nya lubang asap dapur pada rumah. Dan di dukung dengan tidak adanya ventilasi sebagai pertukaran udara serta cahaya mataahari yang masuk sedikit berpengaruh terhadap kejadian penyakit TBC Paru.

Secara umum, kondisi fisik yang termasuk penilaian baik dengan kejadian penyakit TBC Paru yaitu sebanyak 6 rumah (10\%), rumah dengan kondisi fisik penilaian cukup dengan kejadian penyakit TBC Paru sebanyak 14 rumah $(23,3 \%)$, rumah dengan kondisi fisik penilaian kurang dengan kejadian penyakit TBC Paru sebanyak 40 rumah $(66,7 \%)$. Sedangkan rumah dengan kondisi fisik penilaian baik tanpa disetai kejadian penyakit TBC Paru sebanyak 17 rumah $(19,2 \%)$. Rumah dengan kondisi fisik penilaian cukup tanpa disertai kejadian penyakit TBC Paru sebanyak 14 rumah $(23,3 \%)$. Dan rumah dengan kondisi fisik penilaian kurang tanpa disertai kejadian penyakit TBC Paru sebanyak 29 rumah $(57,5 \%)$.

Dari hasil uji statistik yaitu uji ChiSquare didapatkan hasil bahwa ada hubungan kondisi fisik rumah dengan kejadian penyakit TBC di Wilayah Kerja Puskesmas Simomulyo Kota Surabaya ( $p$ $0,030<0,05)$. Dimana rumah yang memiliki kategori kondisi fisik kurang dikarenakan rumah tersebut memiliki pencahayaan yang tidak memenuhi syarat, ventilasi yang tidak digunakan sebagai mana fungsinya, suhu dan kelembapan yang kurang, dinding terbuat dari papan serta lantai yang masih terbuat dari tanah, kondisi yang padat hunian, di setiap rumah juga masih jarang ditemukan adanya lubang asap dapur. Rumah yang memiliki kategori kondisi fisik kurang tersebut sangat berpengaruh terhadap penularan Mycobacterium tuberculosis.

\section{KESIMPULAN}

Berdasarkan hasil penelitian yang telah dilakukan, maka dapat disimpulkan bahwa ada hubungan antara kondisi fisik rumah dengan kejadian TBC Paru, yang di dapatkan dengan statistik uji ChiSquare nilai $(p 0,030<0,05)$.

\section{SARAN}

Berdasarkan kesimpulan penelitian, maka peneliti merekomendasikan saran bagi pihak puskesmas untuk melakukan pemberian genteng kaca terhadap Penderita TBC Paru, memberikan status ventilasi aktif di setiap rumah Penderita TBC Paru dan Non Penderita TBC Paru. Bagi masyarakat, saran yang diberikan adalah agar peduli terhadap kondisi lingkungan rumah seperti membersihkan sarang laba - laba,, membersihkan debu yang ada di dalam dan sekitar rumah secara rutin, memasang genteng kaca, membuka jendela setiap pagi.

\section{DAFTAR PUSTAKA}

Badan Pusat Statistik, 2016. Luas Wilayah Kota Surabaya Menurut Kelurahan 2016. Diakses pada 20 Oktober 2018. Surabayakota.bps.go.id

Badan Pusat Statistik, 2016. Luas Wilayah Kota Surabaya Menurut Kelurahan 2016. Diakses pada 20 Oktober 2018. Surabayakota.bps.go.id

Dinas Kesehatan Provinsi Jawa Timur, 2016. Profil Kesehatan Provinsi Jawa Timur. Diakses pada 20 Oktober 2018. http://www.depkes.go.id/

Girsang, Merryani, dkk. 2007. Faktor penyebab Kejadian Tuberculosis Serta Hubungannya Dengan Lingkungan Tempat Tinggal di Provinsi Jawa Tengah (Analisis Lanjut Riskesdas 2007). Jawa Tengah. Badan Penelitian dan Pengembangan Kesehatan, Kementerian Kesehatan RJ. hal: 01. 08 Januari 2019. https://www.neliti.com/

Health, NW, 2005. Tuberculosis. Jurnal Tuberkulosis. hal. 1-2, diakses 08 Januari 2019. https://www.health.nsw.gov/

Kementrian Kesehatan Republik Indonesia. 2016. Profil Kesehatan Indonesia. Diakses pada 20 Oktober 
2018. http://www.depkes.go.id/

Keputusan Menteri Kesehatan Republik Indonesia Nomor 829/Menkes/SK/VII/1999 Tentang Persyaratan Kesehatan Perumahan

Mahmuda, Dede, Martya Rahmaniati, 2014. Hubungan Status Rumah Sehat dengan Kejadian Tuberkulosis Paru di Provinsi Banten Tahun 2010 Analisa Riskesdas tahun 2010. Depok. Jurnal Departemen Biostatistik dan Studi Populasi, Fakultas Kesehatan Masyarakat Universitas Indonesia. diakses pada $08 \quad$ Januari 2019. http://www.lib.ui.ac.id/
Notoatmojo, Soekidjo. 2010. Metodologi Penelitian Kesehatan. Jakarta. PT. Rineka Cipta. Revisi Cetakan Pertama : 41-44.

PDPI, 2006. Pedoman Diagnosis \& Penatalaksanaan Tuberkulosis di Indonesia. Hal 13. diakses pada 25 Februari.2019.

https://www.klikpdpi.com/

Peraturan Menteri Kesehatan Republik Indonesia Nomor 67 Tahun 2016 tentang Penanggulangan Tuberkulosis

Undang - Undang Republik Indonesia No 1 Tahun 2011 Tentang Perumahan dan Kawasan Pemukiman 